\title{
AI-Enabled Sensing and Decision-Making for IoT Systems
}

\author{
Hao Qinxia $\mathbb{D}^{1,2}$ Shah Nazir $\mathbb{D},{ }^{3}$ Ma Li, ${ }^{1}$ Habib Ullah Khan $\mathbb{D}^{4},{ }^{4}$ Wang Lianlian, ${ }^{1}$ \\ and Sultan Ahmad iD ${ }^{5}$ \\ ${ }^{1}$ School of Communication and Information Engineering, Xi'an University of Science and Technology, Xi'an 710054, China \\ ${ }^{2}$ School of Safety Science and Engineering, Xi'an University of Science and Technology, Xi'an 710054, China \\ ${ }^{3}$ Department of Computer Science, University of Swabi, Swabi, Pakistan \\ ${ }^{4}$ Department of Accounting \& Information Systems, College of Business \& Economics, Qatar University, Doha, Qatar \\ ${ }^{5}$ Department of Computer Science, College of Computer Engineering and Sciences, Prince Sattam Bin Abdulaziz University, \\ Alkharj 11942, Saudi Arabia
}

Correspondence should be addressed to Hao Qinxia; hao_qinxia@sina.com

Received 8 December 2020; Revised 19 December 2020; Accepted 24 December 2020; Published 5 January 2021

Academic Editor: M. Irfan Uddin

Copyright (c) 2021 Hao Qinxia et al. This is an open access article distributed under the Creative Commons Attribution License, which permits unrestricted use, distribution, and reproduction in any medium, provided the original work is properly cited.

The influential stage of Internet of Things (IoT) has reformed all fields of life in general but specifically with the emergence of artificial intelligence (AI) has drawn the attention of researchers into a new paradigm of life standard. This revolution has been accepted around the globe for making life easier with the use of intelligent devices such as smart sensors, actuators, and many other devices. AI-enabled devices are more intelligent and capable of doing a specific task which saves a lot of resources and time. Different approaches are available in the existing literature to tackle diverse issues of real life based on AI and IoT systems. The role of decision-making has its own importance in the AI-enabled and IoT systems. In-depth knowledge of the existing literature is dire need of the research community to summarize the literature in effective way by which practitioners and researchers can benefit from the prevailing proofs and suggest new solutions for solving a particular problem of AI-enabled sensing and decision-making for the IoT system. To facilitate research community, the proposed study presents a systematic literature review of the existing literature, organizes the evidences in a systematic way, and then analyzes it for future research. The study reported the literature of the last 5 years based on the research questions, inclusion and exclusion criteria, and quality assessment of the selected study. Finally, derivations are drawn from the included paper for future research.

\section{Introduction}

The IoT has developed in all fields of life with the emergence of artificial intelligence and has drawn significant consideration for researchers to shape a new paradigm of life standard. This development has been accepted around the globe for making life easier with the dire emergence and use of diverse smart devices such as sensors, actuators, and many other devices. AI-enabled devices are more intelligent and capable of doing a specific task which saves a lot of resources and time. The applications of IoT, mobile, and network provide paramount way out due to less cost and adaptable features [1]. The key functionality of IoT is to provide links to the accessible resources with reliability, effectiveness, and smart service. The IoT brings smartness typically self- possessed of sensors with smooth functionalities, a remote sever and the network. The scheme is intensive for providing monitoring with multidimensional structures and fundamental suggestion of treatment [2]. The IoT has several massive applications in real life which make life easier [3-9].

Diverse techniques, methods, tools, and approaches are available in the present literature to handle different problems of real life based on AI and IoT systems. The role of decision-making has its own significance in the AI-enabled and IoT systems. A comprehensive knowledge of the current literature is dire necessity of the research community to report the literature in operative way by which practitioners and researchers can take assistance from the present proofs and suggest new-fangled way out for solving issues of AIenabled sensing and decision-making for the IoT system. 
Gierej [10] offered the concept of business model for the corporations employing technologies of IIoT. The method is established for supporting traditional businesses in the evolution of the digital market. Humayun et al. [11] offered a complete report of the prevention, evolution, and mitigation of ransomware in IoT context. Jiang [12] has offered a method to study the IoT progresses, technologies associated to cloud computing and smart cities, and then focused on technologies of IoT and cloud computing. Urquhart and Mcauley [13] offered a method to surface the risks lie for IIoT, drawn on the perspectives of both technical and regulatory.

To facilitate research community, the proposed study presents a systematic literature review (SLR) of the existing literature, organizes the evidences in a systematic way, and then analyzes it for future research. The study reported the literature of the last 5 years based on the research questions, inclusion and exclusion criteria, and quality assessment of the selected study. Finally, derivations are drawn from the included paper for future research.

This paper is organized as follows. Section 2 shows the AI-enabled sensing and decision-making for the Internet of Things system with the support of literature. Section 3 presents library-based study of the related analysis with the details of different representations of data. The paper is concluded in Section 4.

\section{AI-Enabled Sensing and Decision-Making for IoT Systems}

Several approaches are available for the AI-enabled sensing and decision-making in the system of IoT. Li and Kara [14] presented a framework of two steps to design a system architecture and then regulate the criteria of selection for each part of the system. The work is validated with a case study of temperature monitoring. Chatfield and Reddick [15] proposed a framework of smart government performance system based on IoT-enabled system. The framework was applied for conducting the study analysis of IoT cyber security policy, digital policy of technology, and the use of IoT in key application areas in the US federal government level. Dachyar et al. [16] conducted a comprehensive analysis of the research on 26420 research articles focusing on the published materials on IoT research from the start of research on IoT from 2006 till 2018. The study materials were published in different Scopus libraries which discuss mainly the IoT. Dwivedi et al. [17] discussed the important and timely information on the technology of AI and its influence on the future of society and industry while focusing on the developments of AI. Gill et al. [18] exposed influences of the artificial intelligence, Blockchain, and IoT for the cloud computing systems in future. Diverse technologies using these three paradigms were explored with the help of international experts in the field of cloud computing for future and current status of it.

Aldhaheri et al. [19] presented a study with the aim to identify, perform, and evaluate a detailed study of the experimental research on the approaches of AIS for securing the environment of IoT. The systematic literature review protocol was followed in order to collect, analyze, and evaluate the research papers. Argüello Prada [20] presented a study on the applications of IoT in the assessment and management of pain. The study presented literature review from 2000 to 2018 in the five most popular libraries of engineering and medical literature to cover technological and clinical aspects of the area. Duplicated papers were removed along with the articles that do not cover the inclusion criteria. Only sixteen articles were included for the purpose of analysis. The selected studies cover the application of IoT in the pain assessment, and some discuss the enabling technologies for management of pain. Hansen and Bøgh [21] presented a detailed investigation and survey on how AI and IoT are among manufacturing SMEs and explored the existing opportunities and limitations for enabling predictive analytics. Initially, the overview of the IoT and AI-enabled system along with four capabilities are provided, and then review of the literature and its analysis is shown. Feijóo et al. [22] presented the development of technology diplomacy for facilitating the global alignment of governance and AI policy and established AI innovation system. Table 1 provides more details of the materials published in the given years.

\section{Library-Based Analysis of the Literature}

The following query was used for searching relevant materials. The widespread libraries including IEEE, ACM, ScienceDirect, and Tailor \& Francis were searched to identify relevant materials associated to the proposed study.

("Artificial intelligence" OR "AI") AND ("sensing") AND ("decision-making") AND ("Internet of Things" OR "IoT")

The purpose of searching different libraries was to detect most relevant resources associated to the planned research. First, the library of ACM was searched in order to know the number of publications with the ratio per year and the type of publications. Figure 1 presents the total of publications in the mentioned years.

Figure 2 depicts the type of publications and the ratios of number of publications. The figure shows that conference papers are having more percentage followed by journal papers.

The IEEE library was searched to identify the associated materials linked to the proposed study. Figure 3 demonstrates the number of papers published in the mentioned years in the IEEE. The figure shows the increase in the number of publications year-wise.

Figure 4 depicts types of publications with the total amount of papers published in the mentioned library.

The popular library of ScienceDirect was searched to identify the number of relevant publications along with the ratio of publications. Figure 5 depicts the total number of articles in the specified year in the library of ScienceDirect. The figure shows that there is increase in the number of publications year-wise in which more relevant papers are published in year 2020 . 
TABLE 1: Materials published in the given years.

\begin{tabular}{cc}
\hline Year & Reference \\
\hline 2016 & {$[23]$} \\
2017 & {$[14,24,25]$} \\
2018 & {$[26-34]$} \\
2019 & {$[15-18,35-48]$} \\
2020 & {$[19-22,49-69]$} \\
\hline
\end{tabular}

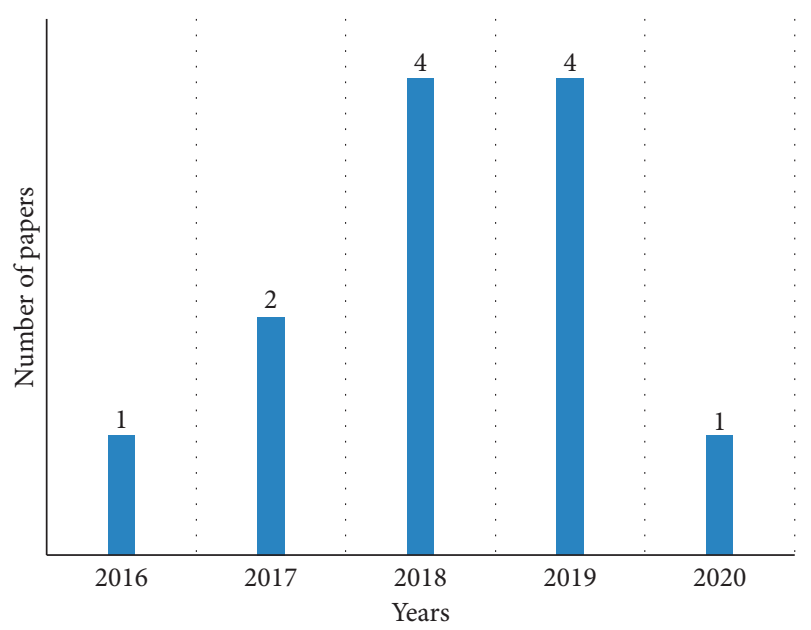

FIgURe 1: Papers published in the mentioned years.

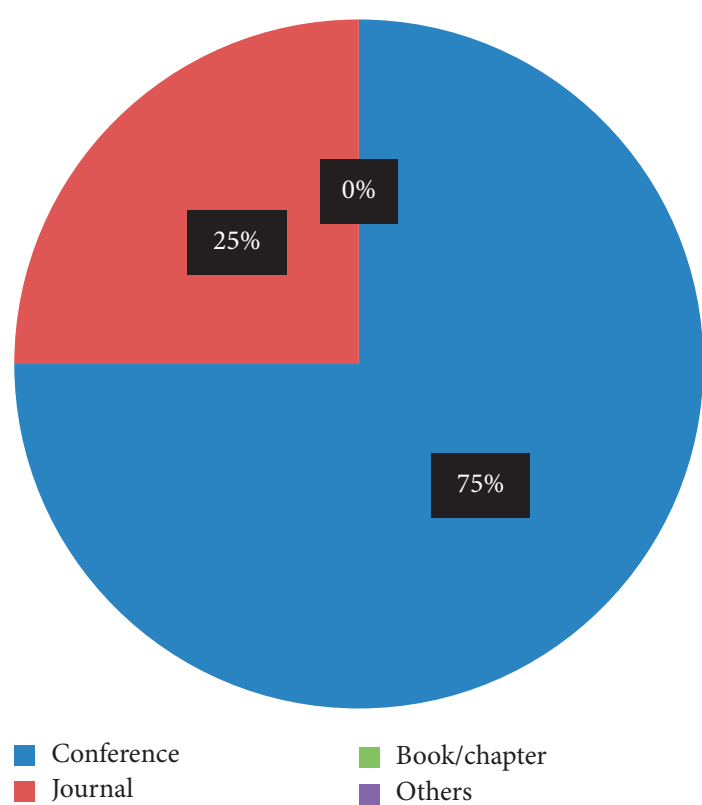

Figure 2: Type of papers along with the total number of publications.

Figure 6 demonstrates types of papers with the number of articles in the specified library. The figure shows that the journal publications are on the top followed by others.

Lastly, the library of Tailor \& Francis was searched for materials relevant to the proposed study. Figure 7 shows the percentages of articles in the specified years.

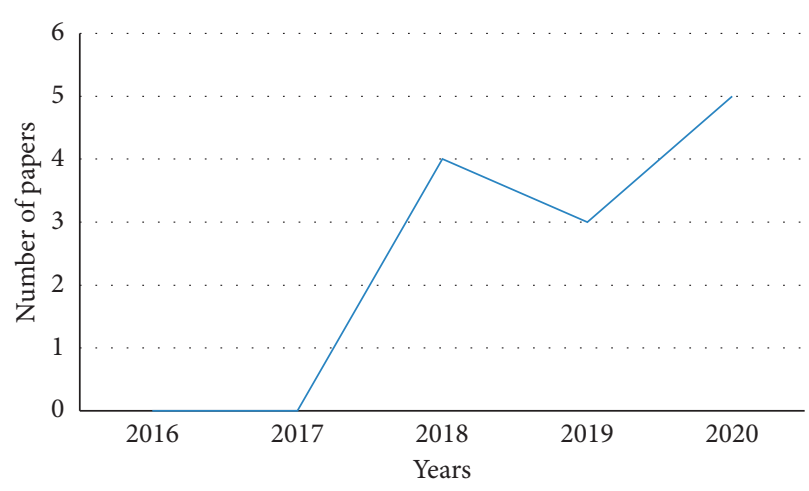

FIgURE 3: Papers published in the mentioned years.

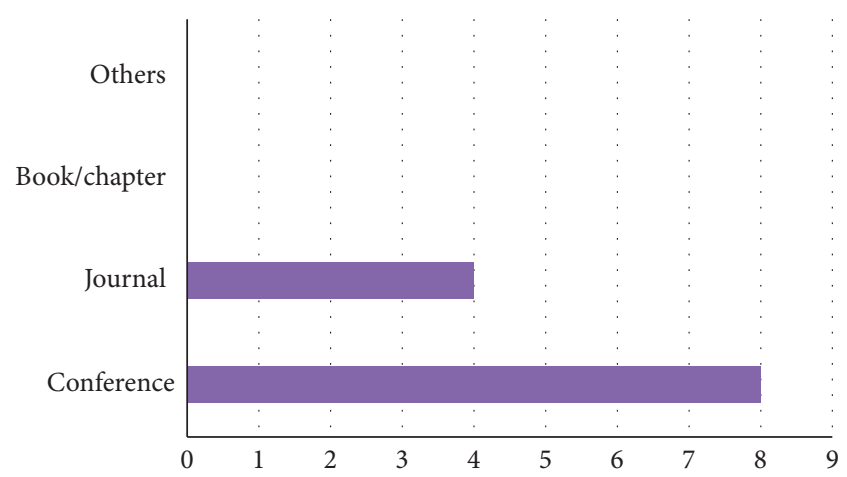

Figure 4: Types of papers along with the number of papers.

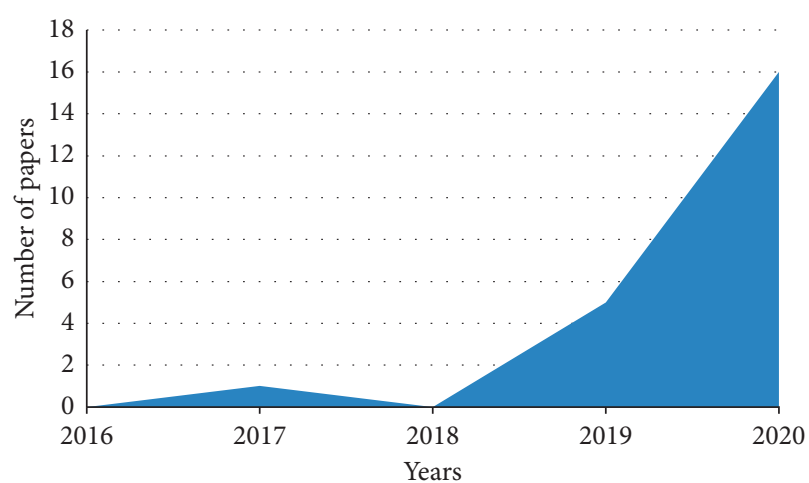

Figure 5: Articles published in the specified years.

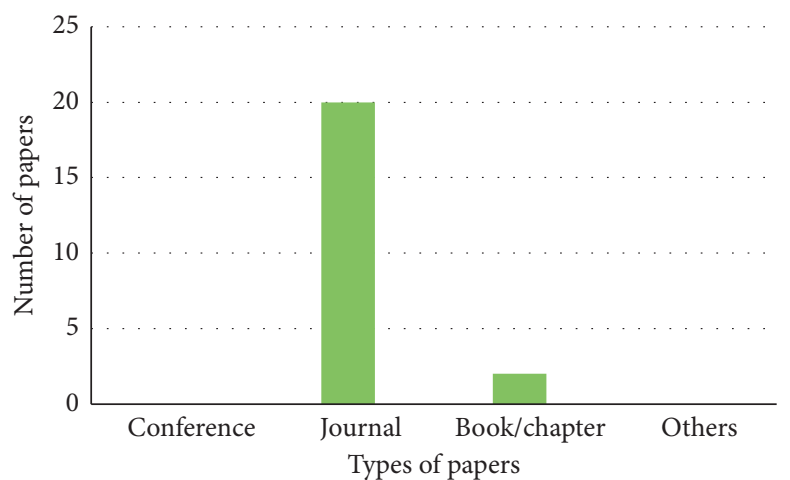

FIgURE 6: Types of papers with the total number of publications. 


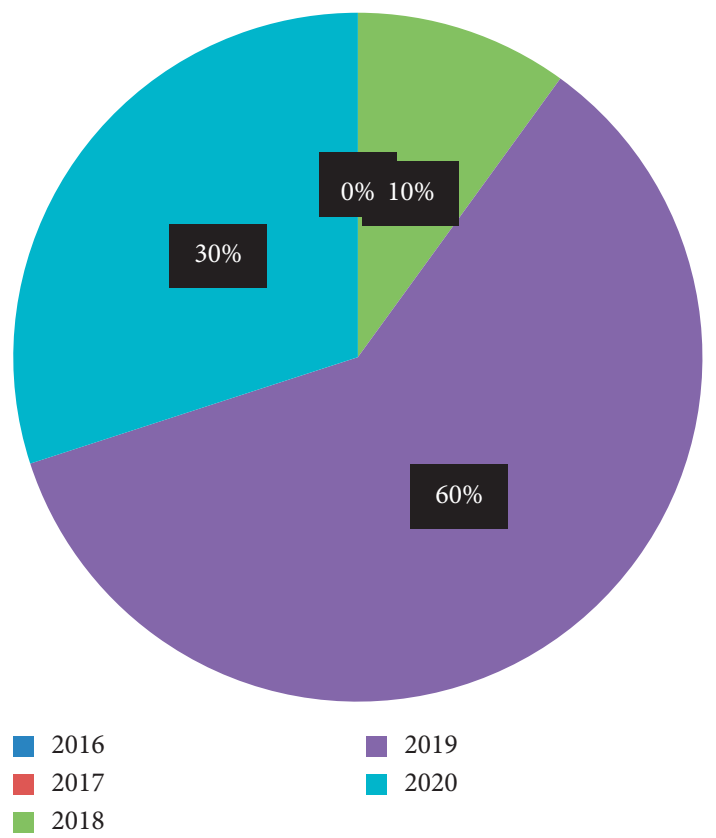

FiguRe 7: Percentages of articles in the specified years.

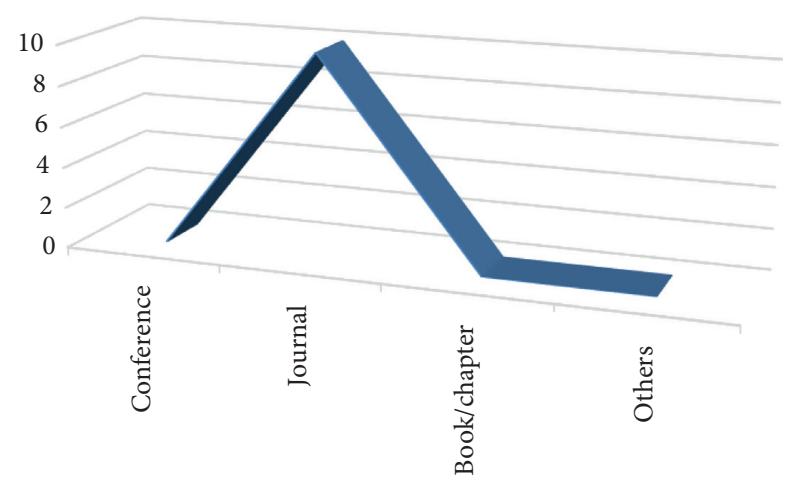

Figure 8: Types of papers with the total number of articles.

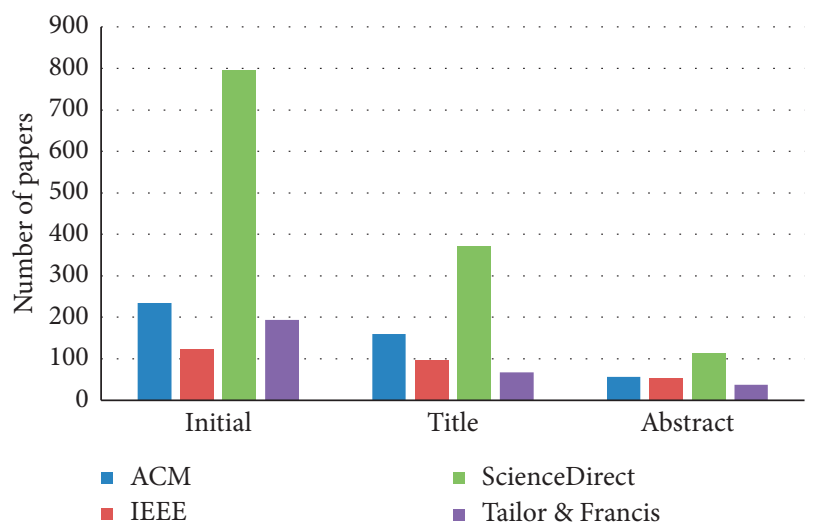

Figure 9: Overall filtering process of papers.

Figure 8 shows the types of papers with the total number of publications in the given library. The figure shows that there is more number of publications in the form of journal.

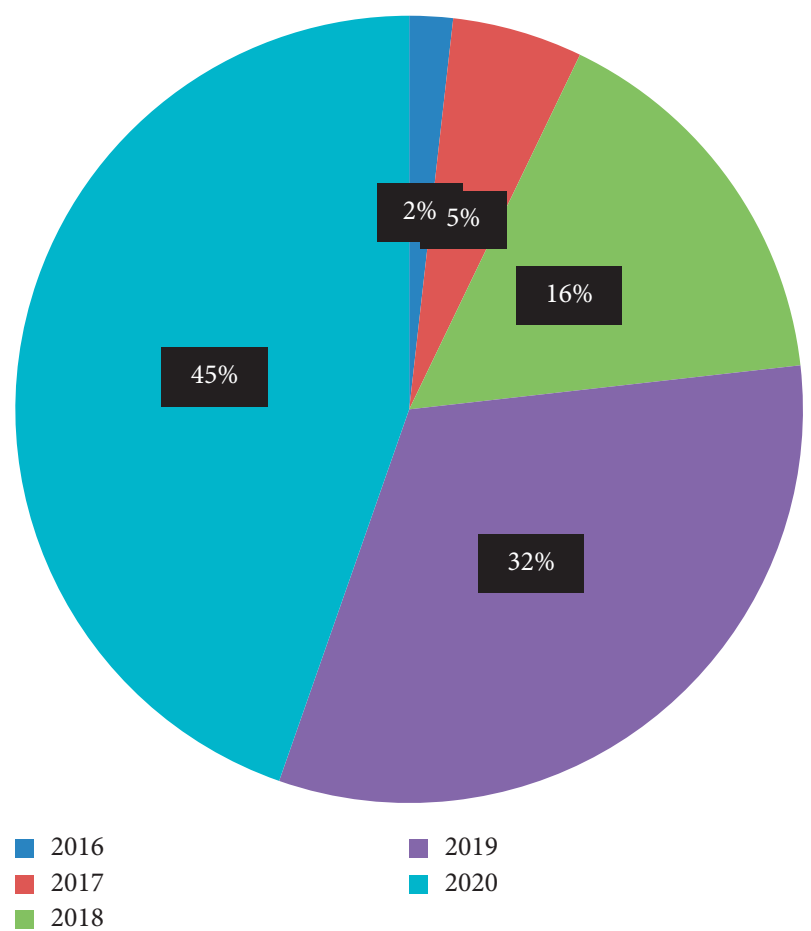

Figure 10: Overall articles in the specified years with total numbers.

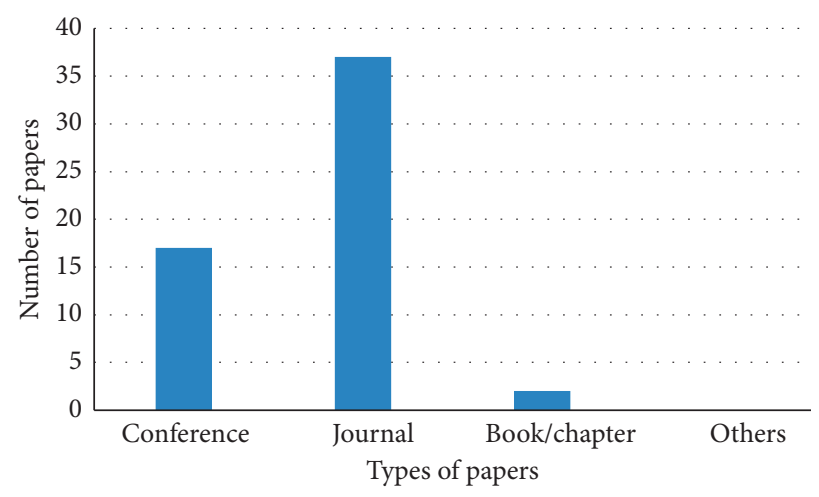

Figure 11: Overall papers with types and total number of articles.

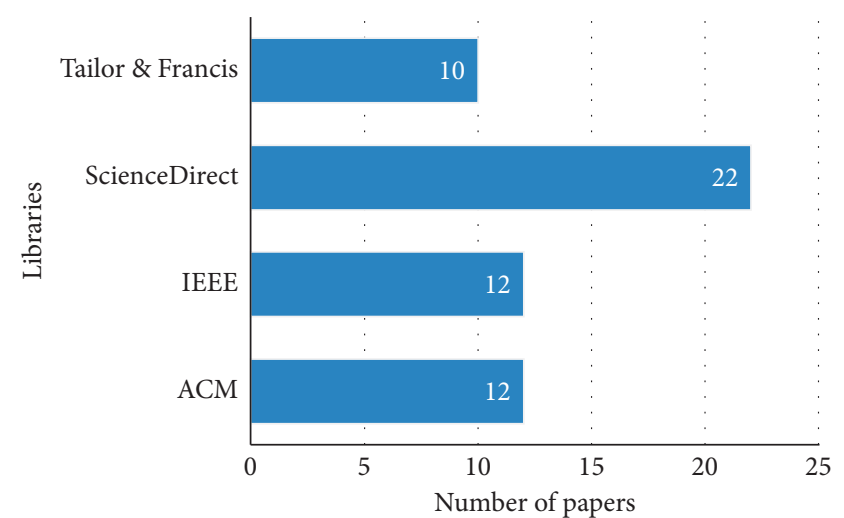

FIGURE 12: Total papers in the given libraries with the total number of publications. 
TABLE 2: Literature related to AI and IoT.

\begin{tabular}{|c|c|}
\hline Ref. no. & Description \\
\hline [70] & Presents data processing of multimedia in system of IoT healthcare \\
\hline [71] & The method explores the issues of maintaining medical devices using data for maintenance and monitoring \\
\hline$[72]$ & Building a system mode in healthcare \\
\hline [73] & To know fog computing in IoT healthcare system \\
\hline [74] & Collecting access and interoperate data of IoT in services of medical care \\
\hline [75] & The application, design, and function of WIoT in system of healthcare \\
\hline [76] & An IoT middleware and patient data processing \\
\hline [77] & Idea of IoT increasing children's health awareness \\
\hline [78] & th in the use of AAL for older adults and to see about tools and techniques of \\
\hline [79] & $\begin{array}{c}\text { The study emphasis is to examine applications of IoT in healthcare, to examine the privacy and security in IoT, and to show a } \\
\text { model of security }\end{array}$ \\
\hline [80] & To examine the usage of IoT in medical and smart healthcare \\
\hline [81] & Describe the implementation of IoT solution in healthcare \\
\hline [82] & To identify and solve medical services' issues in intelligent community \\
\hline [83] & Categorized IoT and AI and their applications \\
\hline [84] & shows system of intelligent healthcare monitoring for activity recognition of human through techniques of mining \\
\hline
\end{tabular}

TABLE 3: Techniques and literature wise categorization.

\begin{tabular}{|c|c|c|}
\hline $\begin{array}{l}\text { Ref. } \\
\text { no. }\end{array}$ & Domain & Description \\
\hline$[85]$ & IoT & Examined the issues, challenges, and open problems of IoT security \\
\hline$[86]$ & IoT & Described vulnerabilities, aims, and goals of security for IoT \\
\hline$[87]$ & $\begin{array}{l}\text { IoT/mobile } \\
\text { computing }\end{array}$ & Security challenges and issues of mobile computing and IoT \\
\hline$[88]$ & $\begin{array}{l}\text { IoT/mobile } \\
\text { computing }\end{array}$ & Security study of IoT-based smart phone \\
\hline [89] & IoT & Examine identification of IoT application, threats, and impacts \\
\hline$[90]$ & $\begin{array}{l}\text { IoT/mobile } \\
\text { computing }\end{array}$ & Tool of mobile application for IoT threat analysis \\
\hline$[91]$ & IoT & Emphases on requirement-based IoT security analysis \\
\hline$[92]$ & IoT & Offered a threat categorization based on dimensions of security \\
\hline$[93]$ & IoT & $\begin{array}{c}\text { Model of classification for analyzing the relation between possible risk and possible vulnerabilities in } \\
\text { devices of home automation }\end{array}$ \\
\hline$[94]$ & IoT & Described the IoT problem analysis and delivered planned way out \\
\hline [95] & IoT & Threats and attacks based IoT analysis \\
\hline$[96]$ & IoT & Analyzing areas of IoT security \\
\hline [97] & Mobile computing & Security study of mobile device to device network through android operating system \\
\hline$[98]$ & IoT & Described the layer-based IoT security analysis \\
\hline [99] & IoT & Architecture-based analysis in light of security requirements \\
\hline$[100]$ & IoT & Study of vulnerability, privacy, and security concerns for IoT \\
\hline$[101]$ & IoT & Analysis of associated IoT attack surfaces and vulnerabilities from IoT OWASP framework \\
\hline$[102]$ & IoT & Described classification of IoT threat and vulnerabilities \\
\hline$[103]$ & IoT & IoT threats and attacks based study \\
\hline$[104]$ & IoT & Model of risk evaluation for tackling the issues of security in IoT ecosystem \\
\hline [105] & IoT & Analyzing trust-based IoT recommendation approaches in IoT \\
\hline
\end{tabular}

After the search process, relevant materials are identified, and after analyzing and filtering the libraries based on initial, title, abstract, and content, the total number is shown. Figure 9 shows the overall filtering process of papers.

Figure 10 shows the overall papers published in the specified years with the total number of articles. The figure shows that more number of papers is published in year 2020 .
Figure 11 depicts the overall papers with number and type of articles published in the specified libraries.

Figure 12 depicts the total papers published in the specified libraries. The figure shows that more relevant papers are published in the library of ScienceDirect.

Table 2 provides the details of the relevant literature published on IoT and AI. 
Table 3 shows the techniques and details of the literature based on categorization of the domain for IoT and AI-enable systems.

\section{Conclusion}

The IoT has transfigured all aspects of life and has drawn the attention of researchers into a new paradigm of life standard to survive. The uprising of IoT has been recognized around the world for making life easier with the use of intelligent devices such as smart sensors, actuators, and many other devices. AI-enabled devices are more intelligent and capable of doing a specific task which saves a lot of resources and time. Different approaches are available in the existing literature to tackle diverse issues of real life based on AI and IoT systems. The role of decision-making has its own importance in the AI-enabled and IoT systems. In-depth knowledge of the existing literature is dire need of the research community to summarize the literature in effective way by which practitioners and researchers can take support of the available proofs and propose new solutions for solving a particular problem of AI-enabled sensing and decisionmaking for IoT system. To facilitate research community, the proposed study presents a systematic literature review of the existing literature, organizes the evidences in a systematic way, and then analyzes it for future research. The study reported the literature of the last 5 years based on the research questions, inclusion and exclusion criteria, and quality assessment of the selected study. Finally, derivations are drawn from the included paper for future research.

\section{Data Availability}

No data were used to support this study.

\section{Conflicts of Interest}

The authors declare no conflicts of interest regarding this paper.

\section{Acknowledgments}

This work was sponsored in part by the Youth Program of National Natural Science Foundation of China (51804248).

\section{References}

[1] S. Tyagi, A. Agarwal, and P. Maheshwari, "A conceptual framework for IoT-based healthcare system using cloud computing," in Proceedings of the 2016 6th International Conference-Cloud System and Big Data Engineering (Confluence), pp. 503-507, IEEE, Noida, India, January 2016.

[2] Y. Yuehong, Y. Zeng, X. Chen, and Y. Fan, "The internet of things in healthcare: an overview," Journal of Industrial Information Integration, vol. 1, pp. 3-13, 2016.

[3] S. Nazir, Y. Ali, N. Ullah, and I. García-Magariño, "Internet of things for healthcare using affects of mobile computing: a systematic literature review," Wireless Communications and Mobile Computing, vol. 2019, Article ID 5931315, 20 pages, 2019.
[4] H. Chen, S. Khan, B. Kou, S. Nazir, W. Liu, and A. Hussain, "A smart machine learning model for the detection of brain hemorrhage diagnosis based internet of things in smart cities," Complexity, vol. 2020, Article ID 3047869, 10 pages, 2020.

[5] R. Amin, S. Nazir, and I. García-Magariño, "A collocation method for numerical solution of nonlinear delay integrodifferential equations for wireless sensor network and internet of things," Sensors, vol. 20, 2020.

[6] A. Ahmad, "Towards an improved energy efficient and endto-end secure protocol for IOT health care applications," Security and Communication Networks, vol. 2020, Article ID 8867792, 10 pages, 2020.

[7] I. García-Magariño, M. M. Nasralla, and S. Nazir, "Real-time analysis of online sources for supporting business intelligence illustrated with Bitcoin investments and IoT sensors in smart cities," Eectronics, vol. 9, 2020.

[8] B. Liao, Y. Ali, S. Nazir, L. He, and H. U. Khan, "Security analysis of IoT devices by using mobile computing: a systematic literature review," IEEE Access, vol. 8, pp. 120331120350, 2020.

[9] L. Wang, Y. Ali, S. Nazir, and M. Niazi, "ISA evaluation framework for security of internet of health things system using AHP-TOPSIS methods," IEEE Access, vol. 8, 2020.

[10] S. Gierej, "The framework of business model in the context of industrial internet of things," Procedia Engineering, vol. 182, pp. 206-212, 2017.

[11] M. Humayun, N. Z. Jhanjhi, A. Alsayat, and V. Ponnusamy, "Internet of things and ransomware: evolution, mitigation and prevention," Egyptian Informatics Journal, 2020.

[12] D. Jiang, "The construction of smart city information system based on the Internet of Things and cloud computing," Computer Communications, vol. 150, pp. 158$166,2020$.

[13] L. Urquhart and D. McAuley, "Avoiding the internet of insecure industrial things," Computer Law \& Security Review, vol. 34, no. 3, pp. 450-466, 2018.

[14] W. Li and S. Kara, "Methodology for monitoring manufacturing environment by using wireless sensor networks (WSN) and the internet of things (IoT)," Procedia CIRP, vol. 61, pp. 323-328, 2017.

[15] A. T. Chatfield and C. G. Reddick, "A framework for Internet of Things-enabled smart government: a case of IoT cybersecurity policies and use cases in U.S. federal government," Government Information Quarterly, vol. 36, no. 2, pp. 346357, 2019.

[16] M. Dachyar, T. Y. M. Zagloel, and L. R. Saragih, "Knowledge growth and development: internet of things (IoT) research," Heliyon, vol. 5, no. 8, Article ID e02264, 2019.

[17] Y. K. Dwivedi, L. Hughes, I. Elvira et al., "Artificial Intelligence (AI): multidisciplinary perspectives on emerging challenges, opportunities, and agenda for research, practice and policy," International Journal of Information Management, Article ID 101994, 2019.

[18] S. S. Gill, S. Tuli, M. Xu et al., "Transformative effects of IoT, Blockchain and Artificial Intelligence on cloud computing: evolution, vision, trends and open challenges," Internet of Things, vol. 8, Article ID 100118, 2019.

[19] S. Aldhaheri, D. Alghazzawi, L. Cheng, A. Barnawi, and B. A. Alzahrani, "Artificial Immune Systems approaches to secure the internet of things: a systematic review of the literature and recommendations for future research," Journal of Network and Computer Applications, vol. 157, Article ID 102537, 2020. 
[20] E. J. Argüello Prada, "The Internet of Things (IoT) in pain assessment and management: an overview," Informatics in Medicine Unlocked, vol. 18, p. 100298, 2020.

[21] E. B. Hansen and S. Bøgh, "Artificial intelligence and internet of things in small and medium-sized enterprises: a survey," Journal of Manufacturing Systems, 2020.

[22] C. Feijóo, Y. Kwon, J. M. Bauer et al., "Harnessing artificial intelligence (AI) to increase wellbeing for all: the case for a new technology diplomacy," Telecommunications Policy, vol. 44, no. 6, Article ID 101988, 2020.

[23] Z. Zhou, K.-F. Tsang, Z. Zhao, and W. Gaaloul, "Data intelligence on the internet of things," Personal and Ubiquitous Computing, vol. 20, no. 3, pp. 277-281, 2016.

[24] P. Khanna and A. Sharma, "Integrating SCM with internet of things: implication on HR management," in Proceedings of the Second International Conference on Internet of Things, Data and Cloud Computing, Cambridge, UK, March 2017.

[25] M. Randles, P. Johnson, and A. Hussain, "Internet of things eco-systems: assured interactivity of devices and data through cloud based team work," in Proceedings of the Second International Conference on Internet of Things, Data and Cloud Computing, Cambridge, UK, March 2017.

[26] A. O. Akmandor, H. Yin, and N. K. Jha, "Simultaneously ensuring smartness, security, and energy efficiency in Internet-of-Things sensors," in Proceedings of the 2018 IEEE Custom Integrated Circuits Conference (CICC), pp. 1-8, San diego, CA, USA, April 2018.

[27] P. Ganguly, A. Bose, K. Chakraborty, A. Chakrabarti, and A. K. Dasgupta, "Development of a multi-fog based water quality monitoring system using bio-sensing platform," in Proceeding of the 2018 IEEE International Symposium on Smart Electronic Systems (iSES) (Formerly iNiS), pp. 223228, Hyderabad, India, December 2018.

[28] G. Martins, C. M. d. Farias, and L. Pirmez, "Athena: a knowledge fusion algorithm for the internet of things," in Proceedings of the 14th ACM International Symposium on QoS and Security for Wireless and Mobile Networks, Montreal, QC, Canada, November 2018.

[29] R. Perez-Torres, C. Torres-Huitzil, and H. Galeana-Zapien, "An on-device cognitive dynamic systems inspired sensing framework for the IoT," IEEE Communications Magazine, vol. 56, no. 9, pp. 154-161, 2018.

[30] S. Sanaei, B. Majidi, and E. Akhtarkavan, "Deep multisensor dashboard for composition layer of web of things in the smart city," pp. 211-215, Proceedings of the 2018 9th International Symposium on Telecommunications (IST), Tehran, Iran, December 2018.

[31] M. Serrano, H. N. Dang, and H. M. Q. Nguyen, "Recent advances on artificial intelligence and internet of things convergence for human-centric applications: internet of things science," in Proceedings of the 8th International Conference on the Internet of Things, Santa Barbara, CA, USA, October 2018.

[32] E. Siow, T. Tiropanis, and W. Hall, "Analytics for the internet of things: a survey," ACM computing surveys (CSUR), vol. 51, no. 4, 2018.

[33] S. Wachter, "The GDPR and the Internet of Things: a threestep transparency model," Law, Innovation and Technology, vol. 10, no. 2, pp. 266-294, 2018.

[34] X.-m. Zhang, "Application of internet of things technology in agricultural production," in Proceedings of the International Symposium on Big Data and Artificial Intelligence, Hong Kong, Hong Kong, December 2018.
[35] E. Balestrieri, B. France, R. C. Angela et al., "The architecture of an innovative smart T-shirt based on the Internet of Medical Things paradigm," in Proceedings of the 2019 IEEE International Symposium on Medical Measurements and Applications (MeMeA), pp. 1-6, Istanbul, Turkey, June 2019.

[36] H. Elazhary, "Internet of Things (IoT), mobile cloud, cloudlet, mobile IoT, IoT cloud, fog, mobile edge, and edge emerging computing paradigms: disambiguation and research directions," Journal of Network and Computer Applications, vol. 128, pp. 105-140, 2019.

[37] A. Imteaj and M. H. Amini, "Distributed sensing using smart end-user devices: pathway to federated learning for autonomous IoT," in Proceedings of the 2019 International Conference on Computational Science and Computational Intelligence (CSCI), pp. 1156-1161, Las Vegas, NV, USA, December 2019.

[38] J. Johnson, "Artificial intelligence \& future warfare: implications for international security," Defense \& Security Analysis, vol. 35, no. 2, pp. 147-169, 2019.

[39] W. Lee and D.-h. Lee, "Cultural heritage and the intelligent internet of things," Journal on Computing and Cultural Heritage (JOCCH), vol. 12, no. 3, 2019.

[40] M. L. Loper, "Simulation trust and the internet of things," in Proceedings of the Winter Simulation Conference, National Harbor, MA, USA, December 2019.

[41] Y. Lu, "Artificial intelligence: a survey on evolution, models, applications and future trends," Journal of Management Analytics, vol. 6, no. 1, pp. 1-29, 2019.

[42] H. Manglani, G. L. Hodge, and W. Oxenham, "Application of the internet of things in the textile industry," Textile Progress, vol. 51, no. 3, pp. 225-297, 2019.

[43] G. Martins, L. F. Kopp, J. Genta, L. F. R. C. Carmo, and C. M. d. Farias, "A prediction-based multisensor heuristic for the internet of things," in Proceedings of the 15th ACM International Symposium on QoS and Security for Wireless and Mobile Networks, Miami Beach, FL, USA, November 2019.

[44] A. Nduka, J. Samual, S. Elango, S. Divakaran, U. Umar, and R. SenthilPrabha, "Internet of things based remote health monitoring system using arduino," in Proceedings of the 2019 Third International Conference on I-SMAC (IoT in Social, Mobile, Analytics and Cloud) (I-SMAC), pp. 572-576, Palladam, India, December 2019.

[45] H. Samih, "Smart cities and internet of things," Journal of Information Technology Case and Application Research, vol. 21, no. 1, pp. 3-12, 2019.

[46] J. Singh, K. Flaherty, R. S. Sohi et al., "Sales profession and professionals in the age of digitization and artificial intelligence technologies: concepts, priorities, and questions," Journal of Personal Selling \& Sales Management, vol. 39, no. 1, pp. 2-22, 2019.

[47] A. H. Sodhro, M. S. Obaidat, S. Pirbhulal, G. H. Sodhro, N. Zahid, and A. Rawat, "A novel energy optimization approach for artificial intelligence-enabled massive internet of things," in Proceedings of the 2019 Summer Simulation Conference, Berlin, Germany, December 2019.

[48] H. Yang, S. Kumara, S. T. S. Bukkapatnam, and F. Tsung, "The internet of things for smart manufacturing: a review," IISE Transactions, vol. 51, no. 11, pp. 1190-1216, 2019.

[49] M. J. Ahn and Y.-C. Chen, "Artificial intelligence in government: potentials, challenges, and the future," in Proceedings of the 21st Annual International Conference on Digital Government Research, Seoul, Republic of Korea, January 2020. 
[50] A. Banerjee, C. Chakraborty, and M. Rathi, "Chapter 8 medical imaging, artificial intelligence, internet of things, wearable devices in terahertz healthcare technologies," in Terahertz Biomedical and Healthcare Technologies, A. Banerjee, B. Chakraborty, H. Inokawa, and J. Nath Roy, Eds., pp. 145-165, Elsevier, Amsterdam, The Netherlands, 2020.

[51] A. D. Boursianis, "Internet of things (IoT) and agricultural unmanned aerial vehicles (UAVs) in smart farming: a comprehensive review," Internet of Things, Article ID 100187, 2020.

[52] Y. Ding, M. Jin, S. Li, and D. Feng, "Smart logistics based on the internet of things technology: an overview," International Journal of Logistics Research and Applications, pp. 1-23, 2020.

[53] T. Geng and Y. Du, "The business model of intelligent manufacturing with Internet of Things and machine learning," Enterprise Information Systems, pp. 1-19, 2020.

[54] P. Goyal, A. K. Sahoo, T. K. Sharma, and P. K. Singh, "Internet of Things: applications, security and privacy: a survey," Materials Today: Proceedings, 2020.

[55] J. Guan, W. Zhou, S. Kang, Y. Sun, and Z. Liu, "Robot formation control based on internet of things technology platform," IEEE Access, vol. 8, pp. 96767-96776, 2020.

[56] Y. Guo, N. Wang, Z.-Y. Xu, and K. Wu, "The internet of things-based decision support system for information processing in intelligent manufacturing using data mining technology," Mechanical Systems and Signal Processing, vol. 142, p. 106630, 2020.

[57] J. He, L. Kong, T. Frondelius, O. Silvén, and M. Juntti, "Decision triggered data transmission and collection in industrial internet of things," in Proceedings of the 2020 IEEE Wireless Communications and Networking Conference (WCNC), pp. 1-5, Sydney, Australia, May 2020.

[58] W. Z. Khan, M. H. Rehman, H. M. Zangoti, M. K. Afzal, N. Armi, and K. Salah, "Industrial internet of things: recent advances, enabling technologies and open challenges," Computers \& Electrical Engineering, vol. 81, Article ID 106522, 2020.

[59] J. Lee, D. Kim, and D. Niyato, "Market analysis of distributed learning resource management for internet of things: a game-theoretic approach," IEEE Internet of Things Journal, vol. 7, no. 9, pp. 8430-8439, 2020.

[60] V. G. Menon, S. Jacob, S. Joseph, P. Sehdev, M. R. Khosravi, and F. Al-Turjman, "An IoT-Enabled Intelligent Automobile System for Smart cities," Internet of Things, Article ID 100213, 2020.

[61] B. K. Mohanta, D. Jena, U. Satapathy, and S. Patnaik, "Survey on IoT security: challenges and solution using machine learning, artificial intelligence and blockchain technology," Internet of Things, vol. 11, Article ID 100227, 2020.

[62] M. Park, R. Lee, R. Jang, and S. Lee, "KISTI vehicle-based urban sensing dataset," in Proceedings of the 2020 IEEE International Conference on Big Data and Smart Computing (BigComp), pp. 601-604, Busan, South Korea, February 2020.

[63] V. Puri, C. Van Le, S. S. Jagdev, and L. C. Kim, "Chapter 10 smart cervical band: an Internet of Things- and artificial intelligence-based neck pain and cervical spondylosis healing system," in An Industrial IoT Approach for Pharmaceutical Industry Growth, V. E. Balas, V. K. Solanki, and R. Kumar, Eds., pp. 289-304, Academic Press, Cambridge, UK, 2020.

[64] A. Sestino, M. I. Prete, L. Piper, and G. Guido, "Internet of Things and Big Data as enablers for business digitalization strategies," Technovation, vol. 98, p. 102173, 2020/12/01/ 2020.
[65] S. Sholla, R. N. Mir, and M. A. Chishti, "Towards the design of ethics aware systems for the Internet of Things," China Communications, vol. 17, no. 2, pp. 239-252, 2020.

[66] S. Singh, P. K. Sharma, B. Yoon, M. Shojafar, G. H. Cho, and I.-H. Ra, "Convergence of blockchain and artificial intelligence in IoT network for the sustainable smart city," Sustainable Cities and Society, vol. 63, p. 102364, 2020.

[67] S. K. Singh, S. Rathore, and J. H. Park, "BlockIoTIntelligence: a blockchain-enabled intelligent IoT architecture with artificial intelligence," Future Generation Computer Systems, vol. 110, pp. 721-743, 2020.

[68] C. Sun, "Research on investment decision-making model from the perspective of Internet of Things + Big data," Future Generation Computer Systems, vol. 107, pp. 286-292, 2020.

[69] W. Wang, "Data analysis of intellectual property policy system based on Internet of Things," Enterprise Information Systems, pp. 1-19, 2020.

[70] G. Rathee, A. Sharma, H. Saini, R. Kumar, and R. Iqbal, “A hybrid framework for multimedia data processing in IoThealthcare using blockchain technology," Multimedia Tools and Applications, vol. 79, pp. 1-23, 2019.

[71] J. Maktoubian and K. Ansari, "An IoT architecture for preventive maintenance of medical devices in healthcare organizations," Health and Technology, vol. 9, no. 3, pp. 233-243, 2019.

[72] M. N. D. Tuan, N. N. Thanh, and L. Le Tuan, "Applying a mindfulness-based reliability strategy to the Internet of Things in healthcare-A business model in the Vietnamese market," Technological Forecasting and Social Change, vol. 140, pp. 54-68, 2019.

[73] M. M. Dhanvijay and S. C. Patil, "Internet of Things: a survey of enabling technologies in healthcare and its applications," Computer Networks, vol. 153, 2019.

[74] B. Xu, L. Da Xu, H. Cai, C. Xie, J. Hu, and F. Bu, "Ubiquitous data accessing method in IoT-based information system for emergency medical services," IEEE Transactions on Industrial Informatics, vol. 10, no. 2, pp. 1578-1586, 2014.

[75] K. Kai, Z.-b. Pang, and W. Cong, "Security and privacy mechanism for health internet of things," The Journal of China Universities of Posts and Telecommunications, vol. 20, pp. 64-68, 2013.

[76] P. Yang, M. Hanneghan, J. Qi, Z. Deng, F. Dong, and D. Fan, "Improving the validity of lifelogging physical activity measures in an internet of things environment," in Proceedings of the 2015 IEEE International Conference on Computer and Information Technology; Ubiquitous Computing and Communications; Dependable, Autonomic and Secure Computing, pp. 2309-2314, IEEE, Liverpool, UK, October 2015

[77] M. Vazquez-Briseno, C. Navarro-Cota, J. I. Nieto-Hipolito, E. Jimenez-Garcia, and J. Sanchez-Lopez, "A proposal for using the internet of things concept to increase children's health awareness," in Proceedings of the CONIELECOMP 2012, 22nd International Conference on Electrical Communications and Computers, pp. 168-172, IEEE, Puebla, Mexico, February 2012.

[78] P. Rashidi and A. Mihailidis, "A survey on ambient-assisted living tools for older adults," IEEE Journal of Biomedical and Health Informatics, vol. 17, no. 3, pp. 579-590, 2012.

[79] S. R. Islam, D. Kwak, M. H. Kabir, M. Hossain, and K.-S. Kwak, "The internet of things for health care: a comprehensive survey," IEEE Access, vol. 3, pp. 678-708, 2015. 
[80] R. Rashid, M. A. Shah, and EK-Healthcare, "Effectiveness of IoT in the medical field with enhanced features," in Proceedings of the 2018 24th International Conference on Automation and Computing (ICAC), pp. 1-6, IEEE, Tyne, UK, September 2018.

[81] S. Zeadally and O. Bello, "Harnessing the power of internet of things based connectivity to improve healthcare," Internet of Things, p. 100074, 2019.

[82] Y. Wang, J. He, H. Zhao, Y.-H. Han, and X.-J. Huang, "Intelligent community medical service based on internet of things," Journal of Interdisciplinary Mathematics, vol. 21, no. 5, pp. 1121-1126, 2018.

[83] R. Shah and A. Chircu, "Iot and AI in healthcare: a systematic literature review," Issues in Information Systems, vol. 19, no. 3, 2018.

[84] A. Subasi, M. Radhwan, R. Kurdi, and K. Khateeb, "IoT based mobile healthcare system for human activity recognition," in Proceedings of the 2018 15th Learning and Technology Conference (L\&T), pp. 29-34, IEEE, Jeddah, Saudi Arabia, February 2018.

[85] M. M. Hossain, M. Fotouhi, and R. Hasan, "Towards an analysis of security issues, challenges, and open problems in the internet of things," in Proceedings of the 2015 IEEE World Congress on Services, pp. 21-28, IEEE, New York, NY, USA, June 2015.

[86] I. Andrea, C. Chrysostomou, and G. Hadjichristofi, "Internet of things: security vulnerabilities and challenges," in Proceedings of the 2015 IEEE Symposium on Computers and Communication (ISCC), pp. 180-187, IEEE, Larnaca, Cyprus, November 2015.

[87] A. Kamilaris and A. Pitsillides, "Mobile phone computing and the internet of things: a survey," IEEE Internet of Things Journal, vol. 3, no. 6, pp. 885-898, 2016.

[88] M. H. Khan and M. A. Shah, "Survey on security threats of smartphones in Internet of Things," in Proceedings of the 2016 22nd International Conference on Automation and Computing (ICAC), pp. 560-566, IEEE, Colchester, UK, September 2016 .

[89] J. Ahamed and A. V. Rajan, "Internet of things (IoT): application systems and security vulnerabilities," in Proceedings of the 2016 5th International Conference on Electronic Devices, Systems and Applications (ICEDSA), pp. 1-5, IEEE, Ras Al Khaimah, UAE, December 2016.

[90] A. Rodríguez-Mota, P. J. Escamilla-Ambrosio, J. Happa, and E. Aguirre-Anaya, "GARMDROID: IoT potential security threats analysis through the inference of android applications hardware features requirements," in Applications for Future Internet, pp. 63-74, Springer, Berlin, Germany, 2017.

[91] S.-R. Oh and Y.-G. Kim, "Security requirements analysis for the IoT," in Proceedings of the 2017 International Conference on Platform Technology and Service (PlatCon), pp. 1-6, IEEE, Busan, Korea, February 2017.

[92] F. Loi, A. Sivanathan, H. H. Gharakheili, A. Radford, and V. Sivaraman, "Systematically evaluating security and privacy for consumer IoT devices," in Proceedings of the 2017 Workshop on Internet of Things Security and Privacy, pp. 1-6, ACM, Dallas, TX, USA, November 2017.

[93] M. Capellupo, J. Liranzo, M. Z. A. Bhuiyan, T. Hayajneh, and G. Wang, "Security and attack vector analysis of IoT devices," in Proceedings of the International Conference on Security, Privacy and Anonymity in Computation, Communication and Storage, pp. 593-606, Springer, Atlanta, GA, USA, July 2017.
[94] A. Tewari and B. Gupta, "Security, privacy and trust of different layers in Internet-of-Things (IoTs) framework," Future Generation Computer Systems, vol. 108, 2018.

[95] R. Gurunath, M. Agarwal, A. Nandi, and D. Samanta, "An overview: security issue in IoT network," in Proceedings of the 2018 2nd International Conference on I-SMAC (IoT in Social, Mobile, Analytics and Cloud)(I-SMAC) I-SMAC (IoT in Social, Mobile, Analytics and Cloud)(I-SMAC), pp. 104-107, IEEE, Coimbatore, India, December 2018.

[96] R. Román-Castro, J. López, and S. Gritzalis, "Evolution and trends in iot security," Computer, vol. 51, no. 7, pp. 16-25, 2018.

[97] K. Liu, W. Shen, C. Yu et al., "Security analysis of mobile device-to-device network applications," IEEE Internet of Things Journal, vol. 6, no. 2, pp. 2922-2932, 2018.

[98] M. A. Khan and K. Salah, "IoT security: review, blockchain solutions, and open challenges," Future Generation Computer Systems, vol. 82, pp. 395-411, 2018.

[99] M. Ammar, G. Russello, and B. Crispo, "Internet of Things: a survey on the security of IoT frameworks," Journal of Information Security and Applications, vol. 38, pp. 8-27, 2018.

[100] A. Girma, "Analysis of security vulnerability and analytics of internet of things (IOT) platform," in Information Technology-New Generations, pp. 101-104, Springer, Berlin, Germany, 2018.

[101] G. Lally and D. Sgandurra, "Towards a framework for testing the security of IoT devices consistently," in International Workshop on Emerging Technologies for Authorization and Authentication, pp. 88-102, Springer, Berlin, Germany, 2018.

[102] I. Sahmi, T. Mazri, and N. Hmina, "Security study of different threats in internet of things," in The Proceedings of the Third International Conference on Smart City Applications, pp. 785-791, Springer, Berlin, Germany, 2018.

[103] F. Meneghello, M. Calore, D. Zucchetto, M. Polese, and A. Zanella, "IoT: internet of Threats? A survey of practical security vulnerabilities in real IoT devices," IEEE Internet of Things Journal, vol. 6, 2019.

[104] G. George and S. M. Thampi, "Vulnerability-based risk assessment and mitigation strategies for edge devices in the internet of things," Pervasive and Mobile Computing, vol. 9, Article ID 101068, 2019.

[105] V. Mohammadi, A. M. Rahmani, A. M. Darwesh, and A. Sahafi, "Trust-based recommendation systems in Internet of Things: a systematic literature review," Human-centric Computing and Information Sciences, vol. 9, no. 1, p. 21, 2019. 